\title{
A Study on Performance Evaluation of Agricultural Listed Companies Based on DEA
}

\author{
Yuan Yiting ${ }^{1, a,{ }^{*}}$ \\ ${ }^{1}$ Nanjing University of Science and Technology, Nanjing, Jiangsu, China \\ aTina147y@163.com
}

Key Word: DEA, Agricultural companies, Performance evaluation, $\mathrm{C}^{2} \mathrm{R}$ model

\begin{abstract}
China is a big agricultural country, and the performance of agricultural listed companies typically reflect the development of agricultural companies. Especially after joining the WTO, it is urgent to address problem that how to effectively evaluate and enhance the performance of agricultural listed companies. Based on the DEA theory, this paper constructs a performance evaluation system which is in line with the characteristics of the industry. This paper chooses 21 financial listed companies financial data from 2013 to 2015, and uses the DEA method to study their organizational performance. Based on the efficiency analysis, scale analysis and relaxation analysis of $\mathrm{C}^{2} \mathrm{R}$ model, relevant suggestions are put forward to improve the comprehensive performance level of agricultural companies in order to promote the development of agricultural economy in China.
\end{abstract}

\section{Introduction}

As a agricultural country, agricultural companies are an important part of China's economy. After a variety of changes brought about by the market economy, the shareholding system reform of agricultural companies has made some achievements, which helps build a group of companies with international advanced technology, flexible business strategies and strong competitive qualities in a short time. However, severe structural contradictions, underdeveloped system reform, weak innovation abilities and other issues have been restricting the development of agricultural companies. At the same time, due to the specialties of agricultural companies, it is common for them to have problems like excessive shares concentration, lacking of effective incentives and regulatory constraints for senior managers, and others issues, which leads to a poor operating performance.

So how to improve the overall performance of agricultural companies? This is the main concern of this paper. Based on a performance evaluation index system with agricultural characteristics, we use the method of data envelopment analysis (DEA) to construct a performance evaluation model which conforms to the business model of agricultural companies, therefore to scientifically and rationally evaluate the operating and strategic performance of agricultural enterprises, and finally help agricultural enterprises improve themselves[4,5,8].

\section{Method Proposed}

Data envelopment analysis (DEA) was first proposed by the famous American mathematician, operational scientist and economic management scientist A. Charnes, W. W. Cooper and E. Rhodes in 1978[1]. And More specifically several studies have used DEA techniques to measure industry performance[2,7].

The basic idea of the DEA method is a linear method in operations research and economics for the estimation of production frontiers. It is used to empirically measure productive efficiency of decision making unit(or DMU). In the DEA theory, efficiency is defined as a ratio of weighted sum of outputs to a weighted sum of inputs, where the weights structure is calculated by means of mathematical programming and constant returns to scale (CRS) are assumed. Through a comprehensive analysis of the input and output ratio, a effective production frontier can be determined. According to the distance between DMU and the frontier, it reveals whether the 
DMU is valid or not. At the same time, with the help of projection methods, it can also be used to analyze the causes of those inefficient DMU, and indicate the direction and extent of improvement.

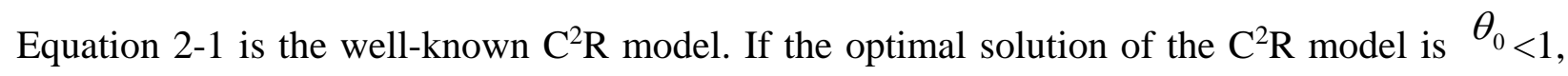
then $\mathrm{DMU}_{\mathrm{j} 0}$ is inefficient; if the optimal solution of the $\mathrm{C}^{2} \mathrm{R}$ model is $\theta_{0}=1$, then $\mathrm{DMU}_{\mathrm{j} 0}$ is weak DEA-efficient; if the optimal solution of the $C^{2} \mathrm{R}$ model is $\theta_{0}=1, \mathrm{~s}^{-}=0, \mathrm{~s}^{+}=0$, then $\mathrm{DMU}_{\mathrm{j} 0}$ is DEA-efficient. The effectiveness of DMU operations is determined by whether it is on the frontier or not[6].

$$
\left\{\begin{array}{l}
\operatorname{Min}\left[\theta-\varepsilon\left(\hat{e}^{T} s^{-}+e^{T} s^{+}\right)\right] \\
\text {s.t. } \sum_{j=1}^{n} x_{j} \lambda_{j}+s^{-}=\theta x_{j 0} \quad \sum_{j=1}^{n} y_{j} \lambda_{j}-s^{+}=y_{j 0} \\
\lambda_{j} \geq 0 \quad \mathrm{j}=1,2, \ldots, \mathrm{n} ; \mathrm{s}^{-} \geq 0 ; \mathrm{s}^{+} \geq 0
\end{array}\right.
$$

\section{Empirical Application}

3.1 Data and Indicators. This study chooses 21 agricultural listed companies from both Shanghai and Shenzhen stock market, and uses their financial data from 2013 to 2015 as research objects, which are also called decision making unit (DMU).

This paper uses the basic $C^{2} R$ model to evaluate the productive efficiency, technical efficiency and the scale efficiency of the DMU. Based on equation 2-1 in 2, I use DEAP software to analyze the performance of selected agricultural listed companies[3].

After analyzing relevant information and financial data, I choose 5 Input indicators and 5 output indicators to reflect the quality of assets and liabilities, the level of financial and material resources, profitability, operational capacity and growth ability of those agricultural listed companies in actual performance evaluation.

Input indicators: the net value of fixed assets at the beginning of the year, intangible assets at the beginning of the year, total operating costs, payroll payable, asset-liability ratio. Among them, the net value of fixed assets at the beginning of the year, total operating costs and payroll payable reflect the input level from perspectives of material, financial and human resources.

Output indicators: Net return on assets, gross profit margin, investment income, net cash flow from operating activities, and capital appreciation rate. Capital appreciation rate $=$ (equity at the end of the year/equity at the beginning of the year) $* 100 \%$, reflecting the company's capital operating efficiency, security and comprehensive growth capacity.

\subsection{Empirical Results}

3.2.1 Overall Efficiency. The overall efficiency equals technical efficiency times scale efficiency, reflecting the overall performance of these sample companies.

The average efficiency value of these sample agricultural companies is 0.728 , the median is 0.905 . The average value is between 0.70 and 0.80 , meaning that the overall performance is satisfying in some degree. The median is greater than the average, indicating that most companies' overall performance is better than the overall average. Statistically, there are 12 companies whose performance is better than the overall average, accounting for $57.14 \%$ of the overall.

Using $\alpha$ to represent the overall efficiency, I divide it into 4 intervals. The details are in table 1.

Table 1. Overall efficiency of sample companies

\begin{tabular}{|c|c|c|}
\hline Intervals & $\begin{array}{c}\text { Numbers of } \\
\text { firms }\end{array}$ & Percentage \\
\hline$\alpha=1$ & 9 & $42.86 \%$ \\
\hline $0.80 \leqq \alpha<1$ & 2 & $9.52 \%$ \\
\hline $0.60 \leqq \alpha<0.90$ & 2 & $9.52 \%$ \\
\hline$\alpha<0.60$ & 8 & $38.10 \%$ \\
\hline
\end{tabular}


From the table we can see that among 21 sample companies, there are 9 companies with a overall efficiency value of 1 , indicating that those agricultural listed companies at the top of the industry are doing very well. In addition, the percentage of selected sample companies are different in different intervals, which shows that the overall efficiency of agricultural listed companies varies from each other. In particular, there are 8 companies with values below 0.6 , indicating that the overall performance of the sample companies are severely polarized.

3.2.2 Technical Efficiency. Technical efficiency refers to the ability to optimize the use of existing resources, that is, the ability to achieve maximum output under conditions that given a certain number of inputs. When the value is 1 , it shows that those agricultural listed companies are highly efficient and at the forefront of the data envelopment, and can obtain better output with the same investment compared with other companies.

The table below shows the average technical efficiency from 2013 to 2015 of 21 sample agricultural companies. The total average technical efficiency value is 0.881 , meaning the input-output ratios of those agricultural listed companies in the past few years were high and stable.

There are 14 companies' technical efficiency value that equals 1 , meaning their input-output ratios are in an ideal state, the overall efficiency of agricultural listed companies are good. However, there are 3 companies' technical efficiency value under 0.600, which are Gansu Dunhuang, Jilin Forest and Fujian Yongan, indicating companies at the end of the whole industry rank have very poor resource utilization efficiency

Table 2. Technical efficiency of Sample companies

\begin{tabular}{|c|c|c|}
\hline No. & DMU & Average technical efficiency value \\
\hline 1 & Gansu Yasheng sh600108 & 0.606 \\
\hline 3 & Gansu Dunhuang sh600354 & 0.590 \\
\hline 4 & Xinjiang Talimu sh600359 & 1.000 \\
\hline 5 & Wanxiang Doneed sh600371 & 1.000 \\
\hline 6 & Xinjiang Korla Pear sh600506 & 1.000 \\
\hline 7 & Heilongjiang Agriculture & 1.000 \\
\hline 8 & sh600598 & 0.729 \\
\hline 9 & Huina Hainan Rubber sh601118 & 1.000 \\
\hline 10 & Hefei Fengle sz000713 & 1.000 \\
\hline 11 & Shandong Denghai sz002041 & 1.000 \\
\hline 12 & Wianshui Zhongxing sz002772 & 1.000 \\
\hline 13 & Starway Bio-tech sz300143 & 0.793 \\
\hline 14 & Hainan Shennong sz300189 & 1.000 \\
\hline 15 & Dahu Aquaculture sh600257 & 1.000 \\
\hline 16 & Shandong Homey sh600467 & 1.000 \\
\hline 17 & CNFC sz000798 & 1.000 \\
\hline 18 & Jilin Forest sh600189 & 1.000 \\
\hline 19 & Fujian Yongan sz000663 & 0.331 \\
\hline 20 & Fortune Ng sh600965 & 0.533 \\
\hline 21 & Hunan New Wellful sh600975 & 0.916 \\
\hline
\end{tabular}

3.2.3 Scale Efficiency. Scale efficiency refers to whether the size of a listed company is in the most appropriate state, reflecting the difference between the actual scale and the optimal scale of production. When the scale efficiency is greater than 1, the listed company has the scale effect, indicating it will increase its input; when the efficiency equals 1,it means the input and output scale is appropriate; when the efficiency is less than 1, the listed company is diminishing in scale.

As can be seen from Figure 1, companies whose scale efficiency equals 1 account for $42.86 \%$, companies whose scale efficiency is less than 1 account for $47.62 \%$, and companies whose scale 
efficiency is greater than 1 accounts for $9.52 \%$, indicating that the scale efficiency of agricultural listed companies is polarized, some sample companies are more promising, while some are shrinking in scales.

This shows that if an agricultural company wants to enhance its input-output ratio in the future, it should focus on the annual scale of efficiency and make appropriate decisions, optimize the allocation of resources, therefore bring out the best economic benefits.

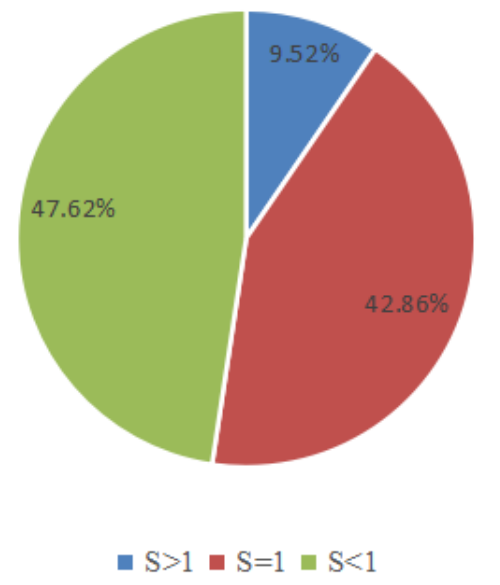

Fig. 1. Scale efficiency distribution of sample companies

3.2.4 Slackness Analysis. Managers are more interested in optimizing the allocation of resources for relatively ineffective agricultural companies, therefore to improve their management performance and achieve relatively better efficiency. Slackness analysis helps understand the improving space of relatively inefficient agricultural companies . If a company's technical efficiency is less than 1, it means it has at least one input or output whose target value (projection value) does not equal to the actual value. The difference between the actual value and the projection value, is the improvable space of those relatively inefficient companies. Table 3 shows the amount of input redundancy and the amount of output deficiency of sample agricultural listed companies, of which the technical efficiency is less than 1 .

In general, neither the input redundancy nor the output deficiency is large, but almost every input indicator is redundant. And about the output situation, 1,3,5 need to improve. These agricultural companies should improve their use of resources to achieve better efficiency. Managers of these agribusinesses can adjust resources distribution according to input redundancy and output deficiency, in order to improve operational efficiency.

Table 3. Input redundancy and output deficiency

\begin{tabular}{|c|c|c|c|c|c|c|c|c|c|c|c|}
\hline \multirow{2}{*}{ DMU } & \multirow{2}{*}{} & \multicolumn{9}{|c|}{ Radial Movement } & \multicolumn{5}{|c|}{ Slack Movement } \\
\cline { 3 - 28 } & & 1 & 2 & 3 & 4 & 5 & 1 & 2 & 3 & 4 & 5 \\
\hline 1 & 0.606 & -0.094 & -0.398 & -0.062 & -0.069 & -0.166 & 0.012 & 0.000 & 0.000 & 0.000 & 0.007 \\
\hline 2 & 0.590 & -0.057 & -0.392 & -0.067 & -0.062 & -0.172 & 0.005 & 0.000 & 0.000 & 0.000 & 0.004 \\
\hline 7 & 0.729 & -0.030 & -0.008 & -0.013 & -0.019 & -0.223 & 0.020 & 0.043 & 0.022 & 0.013 & 0.000 \\
\hline 12 & 0.793 & -0.007 & -0.007 & -0.007 & -0.006 & -0.150 & 0.083 & 0.000 & 0.000 & 0.013 & 0.027 \\
\hline 18 & 0.331 & -0.676 & -0.106 & -0.422 & -0.507 & -0.505 & 0.093 & 0.000 & 0.006 & 0.033 & 0.017 \\
\hline 19 & 0.533 & -0.124 & -0.092 & -0.352 & -0.325 & -0.193 & 0.164 & 0.178 & 0.000 & 0.214 & 0.034 \\
\hline 20 & 0.916 & -0.021 & -0.017 & -0.080 & -0.070 & -0.023 & 0.028 & 0.078 & 0.000 & 0.140 & 0.011 \\
\hline
\end{tabular}

Note: Radial Movement(1=the net value of fixed assets at the beginning of the year; $2=$ intangible assets at the beginning of the year; $3=$ total operating costs; $4=$ payroll payable; $5=$ asset-liability ratio); Slack Movement( $1=$ net return on assets; $2=$ gross profit margin; $3=$ investment income; $4=$ net cash flow from operating activities; $5=$ capital appreciation rate).

3.3 Discussion. The results show that the DEA model is relatively objective to evaluate the performance of agricultural companies. The results are in close agreement with the actual situation, which indicate that that data envelopment analysis model can be used more widely in the performance evaluation of agricultural companies. Through the above analysis of the sample data, 
this paper draws the following conclusions:

(1) In general, agricultural listed companies' overall efficiency is doing well. There are 9 companies on the efficient frontier, accounting for about half of the total number of samples. The average overall efficiency is 0.728 , but here is a gap in efficiency within the industry. Among the 21 companies, there are 3 companies' efficiency score less than 0.600 , indicating a certain degree of polarization of sample companies' overall efficiency.

(2) The overall look of technical efficiency and scale efficiency is ideal, but the gap within the industry is a bit huge. The average technical efficiency and scale efficiency of the listed companies are 0.881 and 0.817 respectively, and the proportion of companies with a score over 0.90 account for $71.43 \%$ and $66.67 \%$ respectively, which indicates that the majority of companies are achieving their goals successfully. However, there are $14.28 \%$ and $28.57 \%$ of the samples companies having a score lower than 0.600 , indicating that companies at the bottom of the industry are way far from their best condition, whose performance need to be improved.

(3) By analyzing the slackness, this paper studies the degree of contribution of input variables to operational performance. Through the projection analysis, the company's overall input and output are satisfying in some degree, but there are still room for improvement. This analysis provides the managers with quantitative basis to improve companies' performance.

\section{Conclusion}

Based on the data envelopment analysis, this paper mainly analyzes the performance management system of China's agricultural listed companies, and evaluates the performance of 21 companies' development status and characteristics using financial data from 2013 to 2015. It is considered that the operating efficiency of China's agricultural listed companies is good, and so are the overall and technical efficiency. But there also is a serious polarization in the industry, and the input-output ratio and cost still have room for improvement.

Learning from the evaluation results, DEA model is relatively objective to evaluate the performance of agricultural companies. Through the analysis, this paper puts forward the following suggestions:

(1) Improve the understanding of performance management, and establish a performanceoriented agricultural company culture. Agricultural companies should actively convey the concept of performance-based management and development to staffs, therefore to eliminate the error and fuzzy understanding of performance management. What's more, it's also important to focus on updating staffs' knowledge and help them establish a correct concept, and finally lay a solid ideological foundation for performance management.

(2) Establish a scientific, systematic and mature performance evaluation management system. Following the guidance from SASAC, it is necessary to optimize the current evaluation system based on the characteristics of the agricultural industry. For instance, using quantitative and qualitative Indicators such as operator performance indicators. So as to strengthen scientific and technological innovation and achieve sustainable development, and ensure the realization of the annual business objectives and the effectiveness of financial control measures.

(3) Implement the strategy of agricultural talent development. Agricultural companies are facing a serious brain drain situation, which has brought huge losses.It's been a long time problems for agricultural companies. To achieve long-term development, agricultural companies must implement a systematic and scientific talent strategy. Agricultural companies should follow the "human resources is the first resource" rule, and earnestly implement the "respect for labor, respect for knowledge, respect for talent, respect for creativity" approach, and adhere to the people-oriented policy. By creating a healthy environment for talent growth, companies can truly the real form an effective mechanism to keep talents.

(4) Improve the level of technological innovation, strengthen quality management, and enhance the comprehensive competitiveness. Strengthen the ability of independent innovation and technological innovation, combine production with advanced research, and lay a solid foundation for the company's long-term development. Also strengthen the supervision and management of 
products' quality, use advanced and scientific methods, and gradually improve the core competitiveness of the agricultural industry.

(5) Pay attention to the role of strategic management. For agricultural listed companies, it is important to establish an independent strategic planning department according to their development needs, which is specifically responsible for business strategy research and the development of future business strategy outline. At the same time, they should pay attention to the tracking and feedback of information.

\section{References}

[1] A. Charnes, W. W. Cooper, E. L. Rhodes, Measuring the efficiency of decision making units. European Journal of Operational Research, vol. 2, pp. 429-444, 1978.

[2] C. C. Sun, Evaluating and bench-marking productive performances of six industries in Taiwan Hsin Chu Industrial Science Park. Expert Systems with Applications, vol. 38, pp. 2195-2205, 2011.

[3] G. E. Halkos, N. G. Tzeremes, Industry performance evaluation with the use of financial ratios: An application of bootstrapped DEA. Expert Systems with Applications, vol. 39, pp. 5872-5880, 2012.

[4] J. F. Yang, A research on the operating performance of agricultural listed companies based on corporate governance. Shanxi: Northwest A\&F University, 2013.

[5] Q. F. Huang, An analysis of the management performance of agricultural listed companies in China under the Non - agricultural Trend. Sichuan: Southwest University of Finance and Economics, 2013.

[6] Q. L. Wei, Data Envelopment Analysis. Science Press: Beijing, 2004.

[7] S. Destefanis, V. Sena, Patterns of corporate governance and technical efficiency in Italian manufacturing. Managerial and Decision Economics, vol. 28, pp. 27-40, 2007

[8] X. Yang, Improvement of Agricultural Enterprise Performance Evaluation Based on EVA and F - AHP, Gansu Nongye, vol. 24, pp. 78-80, 2013. 